\title{
ATENDIMENTO SISTEMATIZADO DE ENFERMAGEM À PESSOA VÍTIMA DE INTOXICAÇÃO POR CARBAMATO (chumbinho)
}

\author{
SYSTEMATIZED NURSING CARE TO VICTIMS OF CARBAMATE INTOXICATION
}

\author{
Beatriz Guimarães Gentil Fraga \\ Dhebora Maria Sardinha Silva ${ }^{2}$ \\ Anderson Reis de Sousa ${ }^{3}$ \\ Thiago da Silva Santana ${ }^{4}$
}

\begin{abstract}
O carbamato, popularmente conhecido como chumbinho, é utilizado como raticida de forma irregular, gerando ocorrências nas unidades de urgência e emergência. Assim, é importante que a comunidade saiba identificar os sinais e sintomas para realizar o primeiro atendimento e que os profissionais tenham habilidade para prestar um atendimento sistematizado. Nesse contexto, o objetivo do presente taralho é levantar as produções científicas referentes ao atendimento sistematizado de enfermagem à pessoa vítima de intoxicação por carbamato, no Brasil, no período de 2012 a 2017. Trata-se, portanto, de uma revisão integrativa da literatura, realizada a partir da seguinte questão norteadora: qual o conhecimento disponível nas bases de dados BVS e Scielo acerca do atendimento sistematizado de enfermagem à pessoa vítima de intoxicação por carbamato? Os trabalhos mostram que a equipe de enfermagem deve inicialmente identificar uma intoxicação por carbamato através dos sinais e sintomas e realizar ações sistematizadas de forma a reverte-los, entre elas, monitorização, lavagem gástrica, intubação endotraqueal, aspiração traqueobrônquica, oxigenoterapia e o uso de carvão ativado. O conhecimento da população bem como dos profissionais da equipe de enfermagem é muito importante para poder agir de forma rápida e eficiente nos casos de intoxicação/envenenamento por carbamato. Todavia, em grande parte dos artigos científicos pesquisados, não foram encontrados dados relativos às ações realizadas pela equipe de enfermagem, pela dificuldade em encontrar prontuários completos.
\end{abstract}

Palavras-chave: Intoxicação por Chumbo. Envenenamento. Assistência de Enfermagem.

Carbamate, popularly known in Brazil as chumbinho, is used as an illegal rodenticide, generating occurrences in hospital emergency wards and emergency care units. In this context, it is important for the community to know how to identify the signs and symptoms in order to provide first care. On the other hand, the professionals must have the ability to provide a systematized care. Thus, the objective of this paper is to gather information from scientific publications on systematized nursing care to victims of carbamate intoxication in Brazil from 2012 to 2017. This study is an integrative review of the literature, based on 6 scientific articles and the following research question: What is the available knowledge in the VHL and SCIELO databases on systematized nursing care of carbamate intoxication victims? The results show that the nursing team should initially identify a carbamate intoxication through signs and symptoms and perform systematized actions to reverse them, such as monitoring, gastric lavage, endotracheal intubation, tracheobronchial aspiration, oxygen therapy and the use of activated carbon The knowledge of the population as well as of the professionals on what to do to save the live of a carbamate intoxication victim is of great importance. Notwithstanding, in most of the scientific articles surveyed, no data were found regarding the actions performed by the nursing team, probably due to the difficulty of finding complete medical records on the subject.

Keywords: Lead Poisoning. Delivery of Health Care. Poisoning

\footnotetext{
${ }^{1}$ Graduanda em Enfermagem pela Faculdade Maria Milza. Cruz das Almas. Bahia. E-mail: fragabia@hotmail.com

${ }^{2}$ Graduanda em Enfermagem pela Faculdade Maria Milza. Cruz das Almas. Bahia. E-mail:

${ }^{3}$ Enfermeiro. Mestre em Enfermagem Pela Escola de Enfermagem da UFBA. Feira de Santana. Bahia. E-mail: areisconsultor@gmail.com

${ }^{4}$ Enfermeiro. Mestre em Enfermagem pela Universidade Estadual de Feira de Santana, Bahia. Feira de Santana. Bahia. E-mail:

ts.santana12@gmail.com
} 


\section{INTRODUÇÃO}

A intoxicação por carbamato, popularmente conhecido como chumbinho, tem sido responsável por grande número de ocorrências nas unidades de urgência e emergência. Seu uso tem causado intoxicações acidentais, bem como tentativas de autoextermínio. Assim, se faz necessário que a comunidade saiba identificar os sinais e sintomas de forma a realizar o primeiro atendimento, bem como que os profissionais tenham habilidade para prestar um atendimento sistematizado, seja este pré ou intra-hospitalar.

A intoxicação por carbamato gera maior proporção de óbitos em indivíduos do sexo masculino (razão homem: mulher de 5:1), com idade entre 25 e 44 anos, observando-se maior incidência na Região Nordeste. Salienta-se que a tentativa de autoextermínio foi o principal fator gerador de intoxicação e possui relação com transtornos de ansiedade e depressão grave (SANTOS; ALMEIDA NETO; CUNHA, 2015).

De acordo com Santos et al. (2015), entende-se por Intoxicação Exógena Aguda (IEA) a exposição a substâncias químicas que sejam capazes de proporcionar sinais e sintomas clínicos de intoxicação e/ou alterações laboratoriais. Os autores citam ainda agrotóxicos, medicamentos, produtos de uso doméstico, cosmético e de higiene pessoal, produtos químicos de uso industrial, drogas, plantas, alimentos e bebidas, como exemplos de materiais que podem gerar IEA.

Especificamente, a intoxicação por carbamato resulta da sua absorção no organismo, seja por via cutânea, respiratória ou digestiva. Já no organismo, inibe as colinesterases, ocorrendo assim diminuição da degradação da acetilcolina e consequente aumento desta no sistema nervoso. $O$ aumento da acetilcolina provocará uma resposta colinérgica, reproduzindo em larga escala seus efeitos sobre o sistema parassimpático, caracterizando os sinais e sintomas da intoxicação.

Pacientes intoxicados por inibidores da colinesterase apresentam sinais e sintomas muscarínicos, nicotínicos e neurológicos, que variam de acordo com a dose e a via de exposição ao agente tóxico. Deve-se destacar o aparecimento de sialorréia, miose, diarréia, fasciculação muscular, convulsões e cianose, que podem evoluir, em casos graves, para coma ou morte (LEÃO et al., 2015).

Por tanto, a intoxicação por carbamato é uma condição clínica emergencial que leva à morte quando o diagnóstico é tardio ou a conduta dos profissionais de saúde inadequada. Por isso a importância dos mesmos estarem capacitados para esse tipo de atendimento, desde a avaliação sintomática, até o diagnóstico e tratamento (DANTAS et al., 2013).

Sabe-se que o carbamato é utilizado como raticida de forma irregular, pois se trata de um agrotóxico que deveria ser de uso exclusivo na lavoura. Essa substância, no entanto, tem sido desviada indevidamente para o uso em ambientes domésticos e como forma de autoextermínio (DANTAS et al., 2013).

As altas taxas de tentativa de suicídio estão intimamente relacionadas às desordens mentais e transtornos psiquiátricos, como transtornos ansiosos e depressão grave (REIS; MARTINS; GAVIOLI, 2013). Mais da metade dos casos de intoxicação ocorreram na própria residência das vítimas, o que talvez sinalize problemas pessoais, financeiros ou problemas de saúde mental prévios (SANTOS, NETO, CUNHA, 2015).

A enfermagem tem papel fundamental na assistência do paciente intoxicado. Por meio de ações sistematizadas e direcionadas ao tipo específico de intoxicação é possível prevenir complicações e perceber precocemente possíveis alterações orgânicas causadas pela substância envolvida (SANTOS; NETO; CUNHA, 2015).

Tendo em vista tais aspectos, foi elaborada a seguinte questão norteadora: qual o conhecimento disponível na base de dados da Biblioteca Virtual em Saúde (BVS) e Biblioteca Eletrônica Científica Online (SCIELO) acerca do atendimento sistematizado de enfermagem à pessoa vítima de intoxicação por carbamato?

Logo, o objetivo do presente estudo é levantar as produções científicas sobre o tema publicadas no Brasil, no período de 2012 a 2017. 
Sendo assim, o estudo pretende contribuir de forma a incentivar pesquisas voltadas para o atendimento às vítimas de intoxicação exógena por carbamato. Por tanto, este poderá servir como base para discussões no que tange ao atendimento, subsidiando ainda propostas de capacitação das equipes de atendimento de emergência com cursos de atualização e aperfeiçoamento, bem como a disseminação deste conhecimento para a comunidade.

\section{METODOLOGIA}

Trata-se de uma revisão integrativa de produções científicas encontradas nas bases de dados da Biblioteca Virtual em Saúde (BVS) e Biblioteca Eletrônica Científica Online (SCIELO). Foram utilizados como descritores chumbinho no campo de busca e "enfermagem" na busca avançada. Nos dois artigos encontrados não foram utilizados filtros por já corresponderem aos critérios de inclusão estipulados: a) artigos publicados em periódicos nacionais; b) artigos publicados no período de 2012 a 2017; c) artigos indexados no idioma português e inglês; d) artigos com foco na intoxicação por carbamato e no atendimento sistematizado de enfermagem à vítima desse tipo de intoxicação.

Numa segunda busca foi utilizado apenas o descritor "carbamato" no campo de pesquisa e "enfermagem" na busca avançada, sendo encontrados 20 trabalhos. A partir da leitura dos títulos e resumos, excluímos aqueles que não se adequavam à temática e área de atuação propostas. Assim, selecionamos 3 publicações para complementar a pesquisa.

Após análise do material de leitura coletado, os dados foram agrupados em quatro categorias: 1) caracterização das produções científicas; 2) perfil das vítimas de intoxicação por carbamato; 3) atendimento pré-hospitalar à vítima e 4) atendimento intra-hospitalar à vítima.

\section{RESULTADOS E DISCUSSÃO}

O corpus documental deste estudo foi constituído de cinco artigos científicos, como apresentamos no Quadro 1.

Os artigos selecionados foram em sua maioria publicados em periódicos da área de Enfermagem, com qualificação e impacto elevado, nos últimos cinco anos, com o foco assistencial direcionado para o atendimento à pessoa vítima de intoxicação por carbamato.

Os artigos foram publicados em periódicos nacionais e internacionais, nos anos de 2012, 2013, 2014, 2015 e 2016, produzidos por profissionais da área de Enfermagem.

As abordagens metodológicas usadas nos artigos foram quantitativas e qualitativas e descrevem o perfil de pacientes vítimas de intoxicação por carbamato, bem como o atendimento sistematizado de enfermagem frente a tais situações.

Os artigos foram publicados em Uberlândia, Fortaleza, São Paulo, Rio de Janeiro e João Pessoa em periódicos da área da Saúde. No entanto, nota-se a falta de publicações relacionadas à intoxicação por carbamato no estado da Bahia.

Nos artigos, foram analisados a motivação e fatores determinantes para a ingestão do carbamato, o perfil epidemiológico das vítimas, bem como a conduta de enfermagem no âmbito pré-hospitalar e intrahospitalar, apresentados no Quadro 01.

A partir da caracterização geral dos artigos selecionados, realizou-se a organização descritiva dos artigos quanto ao delineamento do estudo e instrumentos utilizados, tipo de análise aplicada e principais desfechos encontrados, conforme apresentado no Quadro 02. 
Beatriz Guimarães Gentil Fraga et al.

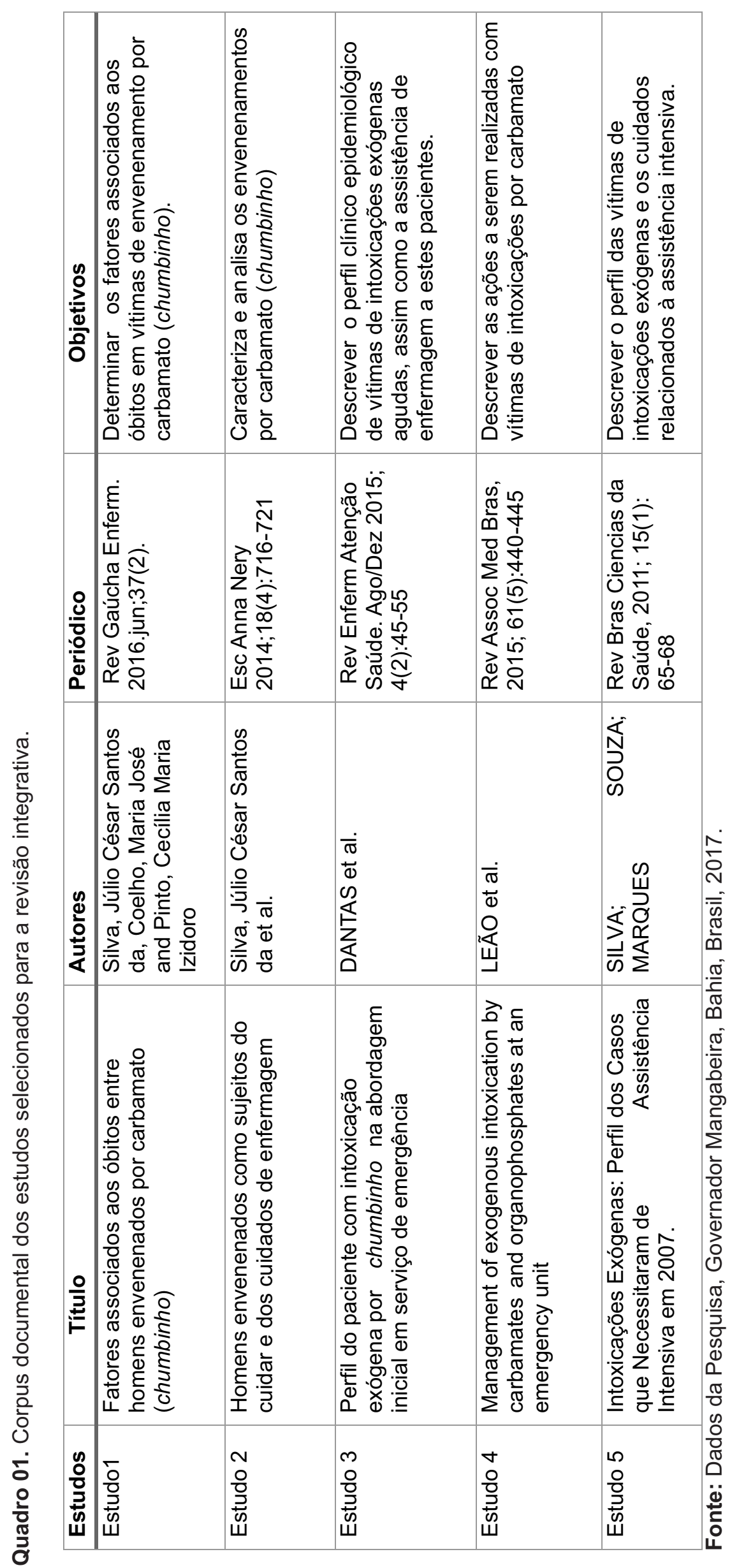


Quadro 02. Caracterização dos estudos selecionados quanto ao tipo de análise aplicada e resultados.

\begin{tabular}{|c|c|c|c|}
\hline Estudos & $\begin{array}{c}\text { Delineamento do } \\
\text { estudo e } \\
\text { instrumentos } \\
\text { utilizados }\end{array}$ & $\begin{array}{c}\text { Tipo de análise } \\
\text { aplicada }\end{array}$ & Desfechos encontrados \\
\hline Estudo 1 & $\begin{array}{l}\text { Estudo } \\
\text { retrospectivo, } \\
\text { epidemiológico } \\
\text { tipo caso- } \\
\text { controle. }\end{array}$ & $\begin{array}{l}\text { Análise descritiva } \\
\text { univariada, com } \\
\text { utilização do } \\
\text { Programa Estatístico } \\
\text { EPI Info 3.5.1 e razão } \\
\text { de chance (ODDS } \\
\text { Ratio-Or) e medida de } \\
\text { associação para } \\
\text { avaliação da relação } \\
\text { entre óbitos por } \\
\text { intoxicação por } \\
\text { carbamato e os } \\
\text { sobreviventes. }\end{array}$ & $\begin{array}{l}\text { O grupo de casos e controle deste estudo foi notificado } \\
\text { por tentativa de suicídio, tendo a via oral como meio } \\
\text { de utilização do carbamato, predominando a } \\
\text { autoingestão, com faixa etária predominante adultos } \\
\text { jovens em idade produtiva. Tempo de exposição entre } \\
20 \text { e } 360 \text { minutos, a média do tempo de exposição foi } \\
\text { de } 178 \pm 132,7 \text { minutos e a mediana de } 120(20 \text { - } 360) \\
\text { minutos. Foi possível inferir que quanto maior o tempo } \\
\text { de exposição maior é a chance de óbito por intoxicação } \\
\text { pelo carbamato. Entre as manifestações clínicas } \\
\text { presentes nos grupos de casos e de controle, } \\
\text { predominaram miose, sialorréia, dispneia, broncorréia, } \\
\text { fasciculações musculares, roncos pulmonares e } \\
\text { sudorese. }\end{array}$ \\
\hline Estudo 2 & $\begin{array}{l}\text { Estudo de caso, } \\
\text { do tipo } \\
\text { exploratório e } \\
\text { descritivo, } \\
\text { qualitativo. }\end{array}$ & $\begin{array}{l}\text { A análise dos dados } \\
\text { foi realizada à luz dos } \\
\text { conceitos de } \\
\text { emergência e de } \\
\text { tipologia de cuidados } \\
\text { de enfermagem, com } \\
\text { o suporte do software } \\
\text { Atlas.ti versão } 6.2 ® \text {. }\end{array}$ & $\begin{array}{l}\text { O público concentrou-se em homens, maioria solteiros, } \\
\text { desempregados, tendo a via oral como meio de } \\
\text { ingestão do carbamato, com presença de alterações } \\
\text { fisiológicas relacionadas ao } \\
\text { envenenamento/intoxicação, tais como hiperglicemia } \\
\text { transitória, variando de } 102 \mathrm{mg} / \mathrm{dl} \text { a } 282 \mathrm{mg} / \mathrm{dl} \text {, } \\
\text { admitidos na unidade de emergência em presença de } \\
\text { pessoas de seu convívio pessoal, com história de } \\
\text { depressão, tentativas de suicídio anteriores, uso de } \\
\text { drogas ilícitas e conflito conjugal e/ou familiar. Foi } \\
\text { utilizado soro fisiológico a 0,9\% e atropina por via } \\
\text { endovenosa, em intervalos regulares, enquanto } \\
\text { intervenção realizada na ocorrência. }\end{array}$ \\
\hline Estudo 3 & $\begin{array}{l}\text { Análise } \\
\text { documental, } \\
\text { retrospectivo, do } \\
\text { tipo descritivo, } \\
\text { quantitativo. }\end{array}$ & $\begin{array}{l}\text { Os dados foram } \\
\text { tabelados no } \\
\text { programa Excel, e } \\
\text { posteriormente, } \\
\text { analisados de forma } \\
\text { estatística. }\end{array}$ & $\begin{array}{l}\text { Foram analisados } 70 \text { casos de intoxicação provocadas } \\
\text { por carbamato no ano de } 2009 \text { registrados em um } \\
\text { serviço de arquivamento médico e estatístico de um } \\
\text { grande hospital. Observou-se frequência elevada para } \\
\text { o sexo masculino, faixa etária entre } 18 \text { e } 28 \text { anos, } \\
\text { residentes na zona urbana. O tempo médio } \\
\text { transcorrido entre a ingestão e a chegada o hospital foi } \\
\text { de duas horas. Os motivos relacionados com a } \\
\text { ingestão do raticida incluem tentativa de } \\
\text { autoextermínio, acidentes individuais e tentativa de } \\
\text { homicídio, ocorridos no âmbito domiciliar, necessitando } \\
\text { de internação hospitalar e transferência para unidades } \\
\text { de maior complexidade, com ocorrência reduzida de } \\
\text { óbitos. Mais da metade obtiveram alta com cura, a } \\
\text { partir de intervenções como: passagem } \\
\text { de sonda nasogástrica (SNG), lavagem gástrica, } \\
\text { monitorização e oximetria de pulso, aferição de sinais } \\
\text { vitais, intubação endotraqueal, aspiração traqueal e } \\
\text { utilização de cateter nasal e máscara de Venturi como } \\
\text { fonte de oxigênio, atropinização e o uso de carvão } \\
\text { ativado por via oral ou SNG. }\end{array}$ \\
\hline
\end{tabular}




\begin{tabular}{|c|c|c|c|}
\hline Estudo 4 & $\begin{array}{l}\text { Estudo descritivo } \\
\text { e quantitativo, } \\
\text { baseado em } \\
\text { análise } \\
\text { retrospectiva da } \\
\text { história clínica de } \\
\text { pacientes } \\
\text { diagnosticados } \\
\text { com intoxicação } \\
\text { por carbamatos } \\
\text { ou } \\
\text { organofosforados. }\end{array}$ & $\begin{array}{l}\text { Os dados foram } \\
\text { submetidos ao teste } \\
\text { de correlação de } \\
\text { Pearson. }\end{array}$ & $\begin{array}{l}\text { Da população amostral analisada, a maioria eram } \\
\text { mulheres, com idade superior a } 35 \text { anos . Os fatores } \\
\text { que levaram à ingestão de carbamato foram } \\
\text { principalmente tentativa de suicídio . Observaram -se } \\
\text { sintomas muscarínicos e nicotínicos, dificuldade } \\
\text { respiratória, transpiração, miose, sialorréia, náusea, } \\
\text { emese, taquicardia eansiedade, que requereram } \\
\text { hospitalização prolongada e a adoção de condutas } \\
\text { terapêuticas como administração de atropina, } \\
\text { lavagens gástricas e prescrição de carvão ativado. }\end{array}$ \\
\hline Estudo 5 & $\begin{array}{l}\text { Estudo descritivo } \\
\text { e retrospectivo. }\end{array}$ & $\begin{array}{l}\text { Para a análise do } \\
\text { banco de dados } \\
\text { foram construídos } \\
\text { tabelas e gráficos que } \\
\text { informaram quais os } \\
\text { agentes tóxicos que } \\
\text { ocasionaram } \\
\text { internação em UTI, e } \\
\text { sua frequência por } \\
\text { mês, com o auxílio } \\
\text { dos recursos do } \\
\text { Microsoft Excel } 2007 .\end{array}$ & $\begin{array}{l}\text { O percentual e frequência absoluta da distribuição } \\
\text { dos casos de internação em Unidade de Terapia } \\
\text { Intensiva (UTI), por intoxicação com carbamatos } \\
\text { mostra valores mais elevados para mulheres e } \\
\text { apontam, como causa da intoxicação, a tentavia de } \\
\text { suicídio. }\end{array}$ \\
\hline
\end{tabular}

Fonte: Dados da Pesquisa, Governador Mangabeira, Bahia, Brasil, 2017.

Tomando como base o conteúdo dos artigos quanto ao delineamento do estudo e instrumentos utilizados, tipo de análise aplicada e principais desfechos encontrados, realizou-se a síntese das conclusões/considerações finais e principais recomendações dos estudos, além da classificação por nível de evidência das produções, apresentadas no Quadro 03.

Quadro 03. Caracterização dos estudos quanto à conclusão, recomendações dos autores e nível de evidência.

\begin{tabular}{|c|c|c|c|}
\hline Estudos & Conclusão/considerações finais & Recomendações & $\begin{array}{l}\text { Nível de } \\
\text { Evidência }\end{array}$ \\
\hline Estudo 1 & $\begin{array}{l}\text { Os achados desta pesquisa } \\
\text { permitiram determinar os fatores } \\
\text { associados aos óbitos por } \\
\text { envenenamento com chumbinho } \\
\text { e apresentaram moderada } \\
\text { associação com a sialorréia, } \\
\text { miose e dispnéia, e uma forte } \\
\text { associação com estertores } \\
\text { pulmonares, broncoespasmos e } \\
\text { os roncos pulmonares. A relação } \\
\text { entre o tempo de exposição e a } \\
\text { possibilidade de cura é } \\
\text { inversamente proporcional, } \\
\text { indicando que a medida que } \\
\text { aumenta o tempo de exposição, } \\
\text { mais graves são as } \\
\text { consequências da intoxicação. }\end{array}$ & $\begin{array}{l}\text { Mecanismos de fortalecimento e qualificação da } \\
\text { atenção primária devem ser promovidos para que a } \\
\text { atenção à saúde do homem não se restrinja à } \\
\text { recuperação, mas garanta, sobretudo, a promoção } \\
\text { da saúde e a prevenção de agravos evitáveis, } \\
\text { através de melhorias na relação do cuidar de si. } \\
\text { Recomenda-se ainda a elaboração de outros } \\
\text { estudos acerca da temática, para favorecer a } \\
\text { difusão do conhecimento sobre o assunto e a } \\
\text { ampliação dos estudos acerca da prevenção das } \\
\text { intoxicações pelo chumbinho, que estão ceifando } \\
\text { uma parcela da população masculina, deixando } \\
\text { clara a necessidade de investigação por parte da } \\
\text { enfermagem que atua na área de emergência, em } \\
\text { especial no atendimento ao grupo masculino, a } \\
\text { partir do desenvolvimento de atividades, através } \\
\text { dos diversos tipos de mídia, visando à divulgação } \\
\text { dos riscos e complicações relacionadas às } \\
\text { intoxicações por chumbinho. }\end{array}$ & 3 \\
\hline
\end{tabular}




\begin{tabular}{|c|c|c|c|}
\hline Estudo 2 & $\begin{array}{l}\text { A análise dos casos evidenciou } \\
\text { que os homens vítimas de } \\
\text { envenenamento/intoxicação por } \\
\text { carbamato têm entre } 28 \text { e } 52 \\
\text { anos. Na maioria dos casos } \\
\text { estudados, os homens foram } \\
\text { socorridos por serviços públicos } \\
\text { de atendimento de emergência, } \\
\text { eram solteiros e todos estavam } \\
\text { desempregados. A via de } \\
\text { intoxicação foi oral, e os sintomas } \\
\text { mais frequêntes foram sialorréia, } \\
\text { sudorese e liberação de } \\
\text { esfíncteres vesical e anal. }\end{array}$ & $\begin{array}{l}\text { Ressalta-se a necessidade de mais pesquisas } \\
\text { dedicadas à saúde do homem que considerem as } \\
\text { questões relacionadas à sua vulnerabilidade e às } \\
\text { perdas sociais e econômicas que os cercam. }\end{array}$ & 4 \\
\hline Estudo 3 & $\begin{array}{l}\text { Os casos de intoxicação por } \\
\text { chumbinho ocorreram } \\
\text { predominantemente em adultos } \\
\text { jovens, do sexo masculino, que } \\
\text { residem na região urbana e estão } \\
\text { associados à tentativa de } \\
\text { suicídio. A via de administração } \\
\text { foi preferencialmente oral e } \\
\text { resultou na necessidade de } \\
\text { internação por aproximadamente } \\
3 \text { dias. Mais da metade dos casos } \\
\text { tiveram desfecho satisfatório com } \\
\text { cura confirmada, o que mostra } \\
\text { que as medidas terapêuticas } \\
\text { foram eficazes. Detectou-se que, } \\
\text { embora os procedimentos } \\
\text { realizados na unidade de } \\
\text { emergência tenham sido } \\
\text { satisfatórios, houve falhas na } \\
\text { sequência de atividades, tais } \\
\text { como ausência de registro dos } \\
\text { procedimentos adotados. }\end{array}$ & $\begin{array}{l}\text { Ressalta-se a necessidade de que os profissionais } \\
\text { de saúde reconheçam os sinais e sintomas do } \\
\text { paciente com intoxicação por chumbinho em tempo } \\
\text { hábil e estejam preparados para a abordagem } \\
\text { inicial, à medida que a conduta adequada } \\
\text { influenciará significativamente na inativação do } \\
\text { toxicante, prevenindo complicações e diminuindo a } \\
\text { mortalidade. Sugere-se a implantação de uma } \\
\text { rotina de registros de modo que as informações } \\
\text { possam ser anotadas de uma forma completa e } \\
\text { consistente no prontuário do paciente, atendendo } \\
\text { assim às questões éticas, legais e de pesquisa. }\end{array}$ & 4 \\
\hline Estudo 4 & $\begin{array}{l}\text { O uso da atropina e carvão } \\
\text { ativado constituiu-se terapêutica } \\
\text { altamente eficaz para tratar os } \\
\text { sinais e sintomas da intoxicação } \\
\text { por carbamato. }\end{array}$ & $\begin{array}{l}\text { Recomenda-se a utilização de atropina e carvão } \\
\text { ativado. }\end{array}$ & 4 \\
\hline Estudo 5 & $\begin{array}{l}\text { As causas das intoxicações } \\
\text { exógenas que demandaram } \\
\text { internações hospitalares } \\
\text { estiveram relacionadas ao } \\
\text { acesso a produtos ilegais como } \\
\text { raticidas (cumarínicos e } \\
\text { carbamatos). Observou-se } \\
\text { associação entre a intoxicação } \\
\text { com chumbinho e } \\
\text { medicamentos neurolépticos, } \\
\text { inseticidas, organofosforados e } \\
\text { piretróides. A tentativa de suicídio } \\
\text { foi, na maioria dos casos, a causa } \\
\text { motivacional da intoxicação. }\end{array}$ & $\begin{array}{l}\text { Por se considerar um agravo à saúde pública, } \\
\text { recomenda-se que haja maior fiscalização e } \\
\text { combate do comércio ilegal de produtos com } \\
\text { potencial de intoxicação. Chama-se a atenção para } \\
\text { a adoção de estratégias educativas como forma de } \\
\text { coibir o uso indiscriminado desses produtos, assim } \\
\text { como o desenvolvimento de ações com vistas à } \\
\text { prevenção do suicídio e redução de acidentes } \\
\text { domésticos por este meio. }\end{array}$ & 4 \\
\hline
\end{tabular}

Fonte: Dados da Pesquisa, Governador Mangabeira, Bahia, Brasil, 2017. 
Para a classificação das evidências dos artigos (Quadro 3) utilizou-se a classificação de Steller (1998), que divide as evidências em 6 níveis:

Nivel I = inclui estudos com realização de metanálise de múltiplos estudos controlados.

Nível II = configurado por estudos experimentais individuais.

Nível III = constitui-se de estudos quase-experimentais e transversais, como ensaio clínico não randomizado, grupos experimentais, grupo único pré e pós-teste além de séries temporais ou caso controle.

Nível IV = corresponde a estudos não experimentais, como pesquisa descritiva, correlacional e comparativa, com abordagem qualitativa e estudos de caso.

Nível $\mathrm{V}=$ apresenta estudos de avaliação de programas obtidos de forma sistemática, como os relatos de caso.

Nível $\mathrm{VI}=$ é representado por estudos de opinião de especialistas, relatos de experiência, consensos, legislações e regulamentos.

Como pode ser visto no Quadro 3, quatro dos cinco artigos selecionados nesta revisão apresentam nível de evidência 4, caracterizando-se como estudos não experimentais, como pesquisa descritiva, correlativa e comparativa, com abordagem qualitativa e estudos de caso.

Nos artigos e pesquisas encontrados e selecionados, foi observado que dentre as inúmeras situações cotidianas vivenciadas no atendimento de emergência nas instituições de saúde, os envenenamentos/intoxicações são uma constante, constituindo quantitativo relevante de casos, principalmente em situações que envolvem carbamato.

A partir da leitura dos artigos percebeu-se que fatores precipitadores podem levar ao envenenamento/intoxicação, fatores esses que são: estado depressivo, conflitos familiares, desemprego, uso de drogas lícitas ou ilícitas além do desemprego no caso de homens.

Outro fator que se destaca quanto à ocorrência das intoxicações por carbamato é o gênero, com predominância do masculino, chamando a atenção para as discussões acerca da construção social das masculinidades, que ainda reforçam modelos hegemônicos que pautam o comportamento de homens associando-os ao ideal de força, virilidade e honra, que os colocam em risco constantemente.

Outra questão associada às masculinidades, destacada nos estudos selecionados nesta revisão, direciona-se para a invisibilidade masculina no tocante ao autocuidado e à promoção da saúde, em que se nota resistência em procurar os serviços ofertados nas unidades de saúde, o que resulta na identificação tardia de fatores de riscos associados ao adoecimento mental, tais como intoxicações e mesmo as tentativas de suicídio.

As mulheres também são acometidas em grande número por estados depressivos desencadeados por transtornos familiares, dificuldades emocionais e de inserção no mercado de trabalho.

Quanto à via de ingestão do chumbinho, observou-se uma clara prevalênica da via oral (DANTAS et al., 2015), talvez pelo fato do chumbinho se apresentar na forma granulada, o que facilita a sua ingestão e dificulta outras vias de administração (SANTOS, et al., 2014).

A partir dos estudos que foram selecionados observou-se que a maioria das vítimas de intoxicação tentaram autoextermínio; no entanto, também há casos de ingestão acidental e de tentativa de homicídio, afetando principalmente pessoas jovens.

O fato das intoxicações autoprovocadas ocorrerem principalmente em centros urbanos pode estar relacionado não só à depressão causada por problemas sociais e laborais, mas também à facilidade de aquisição do chumbinho e à falta de informação da população sobre as consequências da ingestão de produtos que contem carbamato. Neste sentido, não se pode ignorar a importância do enfermeiro no desempenho inerente ao seu papel de educador, pois a prevenção configura-se em um importante elemento na minimização das ocorrências das intoxicações e redução dos fatores complicantes existentes. Assim, faz-se necessário o fortalecimento da educação em saúde para promoção do conhecimento preventivo, além da articulação com outras instâncias de fiscalização para a melhoria da qualidade de vida da população (SANTOS, NETO, CUNHA, 2013).

Dentre os principais resultados observados nos estudos selecionados, observou-se que a 
assistência prestada por não profissionais de saúde às vítimas em situação de intoxicação autoprovocada, no âmbito pré-hospitalar, não foi a adequada, uma vez que o público que presenciava a situação de intoxicação não sabia como agir para ajudar a vítima. Observamos também que o tempo decorrido entre a intoxicação exógena e a assistência médica foi superior a duas horas para 15,7\% dos pacientes investigados. Em consonância, estudo realizado em Pouso Alegre, Minas Gerais, Brasil identificou um tempo de até duas horas entre o início da intoxicação até a chegada da assistência médica (SANTOS; NETO; CUNHA 2013). Esse dado é relevante devido a que o intervalo de tempo decorrente entre a exposição aguda e o atendimento médico representa importante fator de risco inerente ao aumento da mortalidade. Neste sentido, é fundamental que o diagnóstico seja precoce e o tratamento rápido e efetivo (ZAMBOLIN et al., 2008).

O chumbinho causa no indivíduo que o consome síndromes classificadas como muscarínicas, que atingem a musculatura lisa, coração e glândulas exócrinas; e síndrome nicotínica, que atinge as terminações nervosas motoras e os gânglios autonômicos, afetando o Sistema Nervoso Central (SNC). Os efeitos tóxicos do praguicida carbamato podem ser observados entre 30 minutos e duas horas após a sua ingestão. Sua absorção começa na cavidade oral, passando para o estômago, onde é absorvido quase que completamente, e posteriormente sendo distribuído e biotransformado de maneira rápida no organismo (SILVA; SOUZA; MARQUES 2011).

Observou-se também que os pacientes que deram entrada nas unidades hospitalares pouco depois do aparecimento dos primeiros sintomas de intoxicação tiveram uma recuperação mais rápida e com menor número de complicações.

Considerando a rápida ação do tóxico, é importante que a população tenha acesso ao conhecimento sobre medidas de prevenção e de resgate de pessoas nessas circustâncias, a exemplo do Suporte Básico de Vida (SBV), pois esses conhecimentos possibilitam que a população preste os primeiros socorros à vítima, aumentando assim as chances de sobrevivência do paciente ou uma recuperação sem maiores sequelas (SILVA; SOUZA; MARQUES 2011).

No tocante às intervenções realizadas no ambiente assistencial, os estudos não as descrevem com detalhe, e apontam para problemáticas tais como fragilidade nos registros em prontuário, embora ressaltem a importância da assistência de enfermagem no contexto das situações críticas de urgência e emergência.

No que diz a respeito às intervenções propostas, foram priorizadas a manutenção da vida e estabilização do paciente, por meio da manutenção de via aérea pérvia através da aspiração traqueobrônquica, implementada principalmente nos casos de hipersecreção, ou garantia de via aérea avançada, através da intubação traqueal, nos casos em que ocorreram rebaixamento ou ausência da frequência respiratória. Além disso, as equipes também optaram pela sondagem nasogástrica e lavagem gástrica exaustiva com soro fisiológico. Neste sentido, estudo evidencia e chama a atenção para o esvaziamento gástrico, que tem seu benefício máximo se for feito até duas horas após a ingestão (CALIL; PARANHOS 2007).

Sob este aspecto, o emprego da lavagem gástrica não tem sido aplicada enquanto uma maneira estatisticamente significativa para tratar qualquer dos sinais e sintomas investigados, mas para fornecer meios para que a desintoxicação ocorra. Por outro lado, o uso de carvão ativado mostrou-se relevante em intervenções nesse contexto, sendo eficaz tanto no combate aos sinais, quanto aos sintomas em geral (LEÃO et al., 2015). O esvaziamento gástrico nesse tipo de situação pode ser feito em até quatro horas após a ingestão, para que se tenha resultado eficaz e que seja possível promover a estabilização do paciente, com melhoria no quadro (SILVA; SOUZA; MARQUES 2011).

Diante da problemática discutida, e considerando o número crescente de casos de intoxicação por chumbinho, é imprescindível que os profissionais de enfermagem estejam preparados e qualificados para esse tipo de abordagem, uma vez que a brevidade na avaliação dos sinais e sintomas e a rápida inativação do agente reduzem a letalidade consideravelmente.

Ressalta-se ainda a importância da fidedignidade no preenchimento da ficha de notificação compulsória, pois assim se melhora a qualidade das informações, o que pode reverter-se na formulação de indicadores que deem subsídios para a formulação de políticas públicas para enfrentar o fenômeno. 
Nesse sentido, destaca-se a importância da operacionalização do processo de enfermagem e de seus métodos, a exemplo da Sistematização da Assistência de Enfermagem, como estratégia pensada a fim de garantir a qualidade e segurança na saúde.

Enfatiza-se ainda a necessidade do desenvolvimento e ampliação de ações em educação, tanto para a comunidade, quanto para os profissionais de saúde, como forma de ampliar melhorar o atendimento dos casos de intoxicação. Além disso, é importante o envolvimento de gestores e dos órgãos competentes no controle do comércio ilegal do chumbinho.

\section{CONSIDERAÇÕES FINAIS}

Os estudos mostraram que o perfil do paciente intoxicado por chumbinho, atendido na emergência, vem mudando no decorrer dos anos. Hoje o perfil predominante é de adultos-jovens, do gênero masculino, que residem na zona urbana.

Mais da metade das ocorrências de intoxicação tiveram desfecho satisfatório, com cura confirmada, o que mostra que as medidas terapêuticas estão sendo eficazes, no entanto a maior parte necessitou de internamento hospitalar por pelo menos três dias. . O atendimento inicial consistiu, na maioria dos casos, na passagem de sonda nasogástrica com uso de cartão ativado para lavagem gástrica, monitorização de sinais vitais e oximetria de pulso e, em alguns casos, foi necessária a realização de intubação traqueal.

Como consequência desse agravo, investimentos públicos são demandados para o enfrentamento da problemática, onerando o sistema de saúde, além de ocuparam vagas em hospitais, que poderiam estar sendo utilizadas para situações inevitáveis. Neste sentido é necessário fortalecer estratégias que alertem sobre os riscos de consumir chumbinho e dificultem o acesso a ele, com inclusão de profissionais em diferentes esferas, a exemplo dos da saúde, e em especial os da enfermagem, que por estarem intimamente próximos às comunidades, a exemplo do vínculo existente por meio da Estratégia de Saúde da Família, podem contribuir com este avanço.

\section{REFERÊNCIAS}

CALIL, A.M.; PARANHOS, W.Y. O enfermeiro e as situações de emergência (1 ${ }^{\mathrm{a}}$ ed.). São Paulo: Atheneu, 2007.

DANTAS, J. S. S. et al. Perfil do paciente com intoxicação exógena por chumbinho na abordagem inicial em serviço de emergência. Revista Eletrônica de Enfermagem, v. 15, n. 1, p.54-60, 31 mar. 2013. Universidade Federal de Goiás.

LEÃO, S. C. et al. Management of exogenous intoxication by carbamates and organophosphates at an emergency unit. Rev Assoc Med Bras, São Paulo, v. 5, n. 61, p.440-445, abr. 2015.

MARTINS H.S. et al. Emergências Clínicas: Abordagem Prática (5ª ed.). São Paulo: Monde, 2010.

MENDES, K. S. et al. Revisão integrativa: método de pesquisa para a incorporação de evidências na saúde e na enfermagem. Texto Contexto Enfermagem, Florianópolis, v. 4, n. 17, p.758-764, out. 2008.

PINTO M. Chumbinho torna-se caso de saúde pública. Brasil: Ambiente Brasil, 2007.

POMPEO, D. A. et al. Revisão integrativa: etapa inicial do processo de validação de diagnóstico de enfermagem. Acta Paul Enferm, São José do Rio Preto, v. 4, n. 22, p.434-438, 2009.

REIS, L.M. et al.Saúde do homem: internações hospitalares por intoxicação registradas em um centro de assistência toxicológica. Esc Anna Nery 17(3):505-511, 2013.

RODRIGUES, D.S. et al. Apostila de Toxocologia Básica. Centro de Informações Antiveneno da Bahia. Secretaria da Saúde do Estado da Bahia (SESAB). Salvador, 2009. 
SANTOS, R.R.; ALMEIDA NETO, O.P.; CUNHA, C. M. Perfil de vítimas de intoxicações exógenas agudas e assistência de enfermagem. Revista de Enfermagem e Atenção à Saúde, Uberlândia, v. 2, n. 4, p.45-55, ago. 2015.

SILVA, C. C. S. et al. Intoxicações exógenas: perfil dos casos que necessitaram de assistência intensiva em 2007. Revista Brasileira de Ciências da Saúde, Paraíba, v. 15, n. 1, p.65-68, 2011.

SILVA, J. C.S. et al. Homens envenenados como sujeitos do cuidar e dos cuidados de enfermagem. Escola Anna Nery-Revista de Enfermagem], v. 18, n. 4, p.716-721, 2014.

STETLER C.B.et al.. Evidence-based practice and the role of nursing leadershirp. JONA, 28(7-8):45-53, 1998. 